\title{
RESENHA
}

\section{Judicialização da Saúde no Brasil}

Adjudication of Health in Brazil

\section{Ivan Pricken de Bem ${ }^{1}$}

A Judicialização da política é um fenômeno mundial, que emergiu no século XX nas democracias já consolidadas dos Estados de bem-estar social. Em 1988, este paradigma surge no Brasil com a promulgação da Constituição Cidadã, que avançou, vigorosamente, no campo dos direitos sociais como a educação e o trabalho.

Aplicados à saúde, a presença do Poder Judiciário na política é conhecida como judicialização da saúde. Este tema ganha ainda mais importância, num país onde o acesso à saúde é 'direito de todos e dever do Estado e garantido mediante políticas sociais e econômicas que visem à redução do risco de doença e de outros agravos', conforme disposto no art. 196, Seção III, da CF/88.

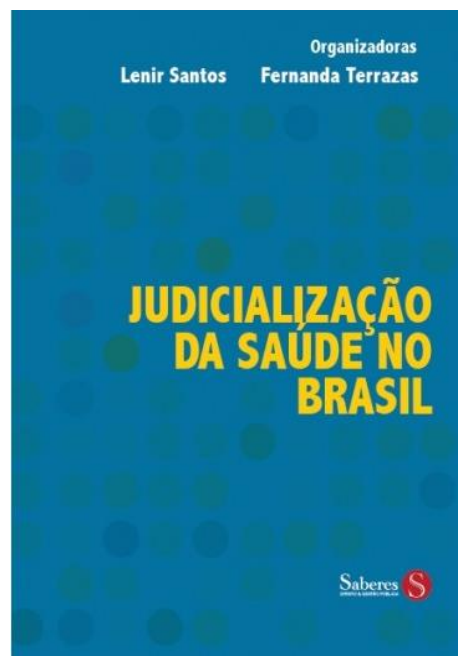

Figura 1: SANTOS, L; TERRAZAS, F. (Org.). Judicialização da Saúde no Brasil. Campinas, SP: Saberes Editora, 2014.
Esse assunto de grande relevância para a saúde pública brasileira é retratado na obra Judicialização da Saúde no Brasil Organizado por Lenir Santos e Fernanda Terrazas - um livro de artigos científicos com seis eixos temáticos (Distribuição de Competência no SUS e a Responsabilidade Solidária; A Judicialização da Saúde e seus Efeitos na Consolidação do SUS; Ações dos Poderes Públicos no Tocante à Judicialização da Saúde; Os Impactos da Judicialização no SUS; Análise das Posições do Poder Judiciário na Judicialização da Saúde; Estudos Clínicos e o Fornecimento do Medicamento no SUS) que reuniu grandes nomes do Direito Sanitário, como o Juiz Federal Clênio Jair Schulze e as consagradas pesquisadoras

Sonia Fleury e Maria Célia Delduque, para debater as temáticas sob várias perspectivas.

\footnotetext{
1 Bacharel em Gestão em Saúde Coletiva pela Universidade de Brasília (UnB). Especialista em Direito Sanitário pela Fundação Oswaldo Cruz. Pesquisador Colaborador no Programa de Direito Sanitário da FIOCRUZ. Brasília, DF, Brasil. E-mail: ivanprk@gmail.com.
} 
A responsabilidade solidária dos entes da federação e seus impactos no Sistema Único de Saúde são pontos-chave de grandes discussões e perpassam diversos estudos que tangem a judicialização da saúde, assim como ocorreu nos primeiros capítulos da referida obra.

De quem é a responsabilidade de garantir prestação de assistência à saúde da população? Os autores dos artigos abrem o debate afirmando que na falha da prestação de serviços, o usuário tem direito de acionar qualquer um dos entes para buscar a tutela jurisdicional da saúde. Nesse sentido, é comum a propositura de ações na Justiça estadual, apenas em desfavor de estados e municípios, solicitando todo tipo de tratamento e medicamento, incluindo aqueles que são financiados pelo Ministério da Saúde.

Nas decisões judiciais, prevalece o entendimento de solidariedade do art.23, Seção Il da Constituição de 1988, que impõe a responsabilidade comum de organização aos três entes, sobrepondo às normas técnicas e infraconstitucionais, mostrando que ainda não há uma análise mais profunda acerca da gestão do Sistema de Saúde.

Um dos capítulos do livro Judicialização da Saúde no Brasil destaca que os gestores de saúde se encontram amarrados à Lei de Responsabilidade Fiscal que, de forma taxativa, impõe as destinações dos gastos nos diversos setores e o seu descumprimento pode acarretar em sanções nas diversas esferas do Direito.

Além do descompasso com o planejamento - instrumento que baliza o orçamento - a judicialização aumenta os custos ao erário que, em detrimento de pequena parcela da população, prejudica o bem-estar de uma coletividade. Isso se deve a transformação do Poder Judiciário, que num papel errôneo de 'ordenador de despesas públicas', deixa de observar as ferramentas básicas de gestão, sobrepondo competências típicas dos outros Poderes.

A crítica que se faz em cima dessas ações são a de que o Judiciário, incumbido de garantir a saúde como direito, atrasa e desestrutura a consolidação do SUS na inobservância de regras organizativas, como a de serviços em rede que dimensionam responsabilidades individuais e solidárias dos entes federativos; assim como, aqueles de incorporação de tecnologias e medicamentos da Agencia Nacional de Vigilância Sanitária (ANVISA) que visam à segurança sanitária.

Por outro lado, os autores dos artigos originais afirmam que as ações do Judiciário conseguiram forçar a atuação dos poderes Executivo e Legislativo, para dar maior 
abrangência ao direito à saúde. Já no seu inicio, a judicialização foi o start para a criação do Programa Nacional de Medicamentos para HIV/AIDS e, recentemente, contribuiu para a criação da Comissão Nacional de Incorporação de Tecnologias no SUS (CONITEC), órgão que assessora o Ministério da Saúde na incorporação, exclusão ou alteração de tecnologias em saúde, trazendo a participação da comunidade como diretriz basilar para a tomada de decisões.

Com um capítulo especial, a Mediação Sanitária também é citada como outra importante contribuição da relação saúde-justiça. Tal prática fortaleceu as funções do Ministério Público, que em seu pleno exercício promove uma interação entre instituições de saúde com a sociedade e uniformizam normas e procedimentos sanitários. Nesse sentido, esta prática permitiu adequado planejamento, com reflexos diretos na elaboração de uma ampla agenda sanitária, reduzindo o fenômeno da judicialização.

O livro Judicialização da Saúde no Brasil traz a tona, sobre múltiplas óticas, o fenômeno do acesso à saúde pelas vias judiciais além de evidenciar que o Sistema Único de Saúde ainda enfrenta muitos desafios, tanto no campo da gestão como no do financiamento, cujo sucesso depende de uma ampla reforma administrativa que vise estabelecer limites de atuação e controle.

Por contar com os melhores pesquisadores e profissionais da área do Direito Sanitário, o exemplar se torna referência para quem deseja se apropriar do tema da judicialização (construção, sistematização e consequências) de forma mais completa e integrada. Lenir Santos e Fernanda Terrazas mostraram-se extremamente cuidadosas na escolha de autores e temas, numa obra que chega em boa hora para os juristas e sanitaristas. Ao leitor, cabe apenas ler e se integrar de um tema tão atual e importante para a saúde pública e coletiva do Brasil.

\section{Referências Bibliográficas}

1 Santos L, Terrazas F. Judicialização da Saúde no Brasil. Campinas: Saberes Editora; 2014. 